\title{
Pharmacological management of nonalcoholic fatty liver disease: Limitations, challenges and new therapeutic opportunities
}

\author{
Eleni A. Karavia, Kyriakos E. Kypreos \\ Pharmacology Department, University of Patras Medical School, Rio, Achaia, Greece
}

\begin{abstract}
Nonalcoholic fatty liver disease (NAFLD) is a spectrum of metabolic disorders ranging from a simple accumulation of excess triglycerides in the liver (hepatic steatosis) to hepatic steatosis with inflammation, fibrosis, and cirrhosis (steatohepatitis or non-alcoholic steatohepatitis (NASH)). Studies in humans and animal models suggested that alterations in hepatic lipid metabolism, increased generation of reactive oxygen species and consequently oxidative stress, changes in mitochondrial function, DNA damage, microbial infections and release of various cytokines may contribute to the pathogenesis of NAFLD and its progression to NASH. Recent data also suggest an important role of the lipoprotein transport system in hepatic lipid deposition. Currently, no drugs are approved for the treatment of NAFLD and NASH and existing pharmacotherapy aims at the management of intercurrent diseases such as obesity, hyperlipidemia, insulin resistance, and type 2 diabetes mellitus. All guidelines acknowledge that any medicines prescribed for NAFLD treatment should be considered as an off-label treatment and that their efficacy and safety should be carefully monitored. Although current pharmacotherapy may seem limited and of questionable efficacy, there is optimism that innovative safe and effective options for the management of the disease will be made available shortly since specialized drugs such as obeticholic acid, elafibranor and cenicriviroc, are presently tested in clinical trials. Given that patients with NAFLD without steatohepatitis or fibrosis have excellent prognosis if they adopt appropriate therapeutic lifestyle changes, it is generally accepted that pharmacological treatments should be limited to those with established NASH and fibrosis while subjects with early manifestations of NAFLD should resort to therapeutic lifestyle and nutritional changes.
\end{abstract}

KEY WORDS: NAFLD, lipoproteins, dyslipidemia, drugs, new therapeutic modalities

\section{Corresponding author:}

Kyriakos E. Kypreos, PhD, University of Patras Medical School,

Department of Pharmacology, Panepistimioupolis, 26500 Rio, Achaia, Greece,

Tel.: +302610969120, Fax: +302610994720,

e-mail:kkypreos@med.upatras.gr,

web: http://www.kyriakoskypreos.com

\section{NAFLD OVERVIEW}

Nonalcoholic fatty liver disease (NAFLD) is a spectrum of metabolic disorders ranging from a simple accumulation of excess triglycerides in the liver (hepatic steatosis) to

Submission: 15.05.2019, Acceptance: 14.06.2019 
hepatic steatosis with inflammation, fibrosis, and cirrhosis (steatohepatitis or non-alcoholic steatohepatitis (NASH))., ${ }^{1,2}$ NAFLD may develop in four distinct stages which according to the British NHS are classified as: i) steatosis which is characterized by a build-up of fat in the liver cells that does not bear any metabolic consequences and is usually diagnosed circumstantially, ii) NASH which is a more serious form of NAFLD, where the hepatic deposition of fat is associated with inflammation, iii) fibrosis, a stage where persistent inflammation causes excess extracellular connective tissue build-up around the liver and nearby blood vessels, though liver may still be available to function normally, and iv) cirrhosis, the most severe and dangerous stage, occurring after years of inflammation, where the liver shrinks and becomes scarred and lumpy. The hepatic damage during this stage is irreversible and may lead to liver failure and hepatocarcinomas. Therefore, it is important that NAFLD is detected in the early stages when tissue damage is still reversible and treatable. In humans NAFLD is usually associated with obesity and oftentimes with cardiovascular disease, insulin resistance and other metabolic perturbations. ${ }^{1-3}$ Thus, it is proposed that NAFLD is the hepatic component of metabolic syndrome. ${ }^{4}$ However, accumulating body of evidence indicates that NAFLD may also be found less frequently in lean subjects $^{5-7}$ possibly due to different etiological factors, mainly environmental and genetic. ${ }^{8}$

The molecular etiology of NAFLD is still not well defined and under investigation. Though aging, hormonal imbalance, and genetic predisposition may contribute to NAFLD it appears that excess caloric dietary intake and sedentary lifestyle are the most common contributors. ${ }^{9,10}$ In terms of the mechanisms, studies in humans and animal models have suggested that alterations in hepatic lipid metabolism, increased generation of reactive oxygen species and consequently oxidative stress, changes in mitochondrial function, DNA damage, microbial infections and release of various cytokines may contribute to the progression of NAFLD to NASH. ${ }^{10-13}$ As detailed below, recent data also suggest an important role of the lipoprotein transport system in hepatic lipid deposition.

\section{THE LIPOPROTEIN TRANSPORT SYSTEM}

It appears that post-prandial management of dietary lipids is an important aspect of NAFLD. Lipoproteins are involved in three major metabolic pathways in plasma: the chylomicron pathway which is responsible for the transport and distribution of dietary lipids, the Very Low Density Lipoprotein (VLDL)/Intermediate density lipoproteins (IDL)/Low Density Lipoprotein (LDL) pathway which is responsible for the transport and distribution of hepatically synthesized lipids, and the HDL pathway which is responsible for transport and redistribution of cholesterol and other lipids among tissues, including liver. Though distinct from each other, these pathways are all metabolically interrelated. Several different proteins, such as apolipoproteins, enzymes, lipid transfer proteins, lipoprotein receptors, and lipid transporters, are required for maintaining plasma lipid homeostasis via these pathways. ${ }^{14}$

Triglyceride-rich lipoproteins comprise chylomicrons, their remnants and VLDL. Chylomicrons are assembled in the intestine. ${ }^{14}$ Dietary lipids absorbed by intestinal epithelial cells are transferred onto apolipoprotein B48 (ApoB48) via intestinal microsomal triglyceride transfer protein (MTTP) to form chylomicrons which are then secreted into circulation via the lymph. In blood, chylomicrons are hydrolyzed by lipoprotein lipase (LPL). This step converts chylomicrons to chylomicron remnants which subsequently acquire apolipoprotein E (ApoE) and are cleared rapidly by members of the $L D L$ receptor (LDLR) superfamily. VLDL are assembled in the liver. ${ }^{14}$ Hepatically synthesized cholesterol and TG are transferred onto apolipoprotein B100 (ApoB-100) via hepatic MTTP to form nascent VLDL particles which are directly secreted into circulation. Like chylomicrons, VLDL TG are then hydrolyzed by LPL, and converted initially to IDL and then to LDL which are also cleared by members of the LDLR superfamily.

The assembly of HDL takes place exclusively in the circulation. ${ }^{15} \mathrm{HDL}$ biogenesis occurs through a complex pathway that involves the lipid transporter ATP-binding cassette A1 (ABCA1) and the plasma enzyme Lecithin:Cholesterol Acyl Transferase (LCAT). ${ }^{16-18}$ In the early steps of HDL formation, lipid-free apolipoprotein A-I interacts with the lipid transporter $A B C A 1$ and acquires phospholipids and cholesterol. Through a series of intermediate steps that are poorly understood, minimally lipidated apoA-I gradually forms discoidal HDL particles which are then converted into spherical particles by the action of LCAT. ${ }^{16}$ ApoA-I on both discoidal and spherical HDL particles interacts functionally with the scavenger receptor class $B$ type I (SR-BI), ${ }^{19-21}$ also known as HDL receptor. Additional steps in the metabolism of HDL involve the transfer of cholesterylesters to VLDL/LDL for eventual catabolism by the LDL receptor through the plasma enzyme cholesteryl-ester transfer protein (CETP), the hydrolysis of phospholipids and residual triglycerides by the various lipases ( $L \mathrm{pL}$, hepatic lipase (HL), and endothelial lipase (EL)), and the transfer of phospholipids from VLDL/LDL to HDL by the action of phospholipid transfer protein (PLTP). ${ }^{14}$

\section{LIPOPROTEINS AND NAFLD}

Through a series of experiments in ApoA-I-deficient 
(apoa $\left.1^{-/}\right)$, LCAT-deficient (/cat $\left.{ }^{-/}\right)$and SR-BI-deficient $\left(\right.$ scarb $\left.^{-/}\right)$mice it was shown that in addition to the classical role of HDL in plasma cholesterol metabolism, it also plays significant role in hepatic lipid deposition.

Lack of classical ApoA-I containing HDL resulted in increased diet-induced hepatic TG deposition and disturbed hepatic histology in apoa $1^{--}$mice compared to their wild-type counterparts, while they exhibited reduced glucose tolerance and insulin sensitivity. ${ }^{22}$ This phenotype was reversed by administration of $A p o A-I_{\text {Milano, a gain }}$ of function mutant of ApoA-I leading to a significant reduction of hepatic lipid deposition and body weight gain. ${ }^{22}$ In agreement with this finding, it was shown that expression of wild-type human ApoA-I in C57BL/6 mice, fed methionine and choline-deficient diet for one week, reduces significantly hepatic lipid deposition induced by the diet. ${ }^{23}$ Along the same lines, administration of varying doses of ApoA-I in New Zealand white rabbits fed a highfat diet for 20 weeks, led to an ApoA-I dose-dependent reduction in hepatic steatosis. ${ }^{24}$

Contrasting the role of ApoA-I in diet-induced obesity and hepatic lipid deposition, Apolipoprotein A-II (ApoA-II), the second most abundant protein of $\mathrm{HDL}^{25}$ appears to rather promote the development of obesity and NAFLD. ${ }^{26}$ Interestingly, the C. $492 \mathrm{~T}>\mathrm{C}$ polymorphism in human ApoA-II gene was associated with increased risk for obesity ${ }^{27}$ and the T265C ApoA-II polymorphism correlated with increased visceral adipose tissue (VAT) mass. ${ }^{28}$

Similarly to ApoA-I-deficiency, LCAT-deficiency was also found to be associated with altered plasma TG metabolism in mice. ${ }^{29} \mathrm{Lcat}^{-/}$mice were prone to diet-induced obesity and hepatic lipid deposition. Administration of human LCAT by adenovirus mediated gene transfer to lcat $^{-/}$mice resulted in a significant improvement of hepatic lipid deposition. ${ }^{29}$ In contrast, deficiency in the HDL receptor SR-BI prevents hepatic lipid deposition and NAFLD development. ${ }^{30}$

Even though the relationship between NAFLD and coronary heart disease is unclear ${ }^{31,32}$ these data strongly support that blood lipoprotein transport is a key link, being as important for NAFLD development ${ }^{22,29,30,33}$ as it is for heart disease and diabetes. Obviously, the precise contribution of each lipoprotein pathway deems further investigation. Moreover, the role of the lipoprotein system in the management of dietary lipids further reinforces the paramount significance of dietary interventions in NAFLD prevention and treatment, as discussed below.

\section{CURRENT PHARMACOLOGICAL INTERVENTIONS}

Currently, no drugs have been officially approved for the treatment of NAFLD and NASH by the US Food and Drug Admin- istration, the European Medicines Agency or other regulatory body. All guidelines for NAFLD treatment acknowledge that any medicines prescribed for the treatment of the disease (Table 1) should be considered as an off-label treatment and that patients should be explicitly informed while critical factors associated with efficacy and safety should be carefully monitored. However, guidelines issued by different medical associations disagree on the degree of benefit of each of the currently prescribed medications. ${ }^{34}$ The main target in the treatment of NAFLD is the management of intercurrent diseases such as obesity, hyperlipidemia, insulin resistance, and type 2 diabetes mellitus (T2DM). ${ }^{32}$ While specialized drugs are under development (Table 2) patients with NAFLD without steatohepatitis or any fibrosis have excellent prognosis if they adopt appropriate therapeutic lifestyle changes (TLC). Therefore, it is generally accepted by all guidelines that pharmacological treatments should be limited to those with established NASH and fibrosis while subjects with early manifestations of NAFLD should resort to TLC, ${ }^{35,36}$ as described below (Table 3).

\section{Insulin sensitizers}

Metformin, a first-line medicine for the treatment of T2DM, appears to have limited efficacy in improving the histological features of NAFLD. ${ }^{37,38}$ Therefore, metformin is not recommended by any guidelines to specifically treat NAFLD. ${ }^{39,40}$ In contrast, pioglitazone (thiazolidinedione), a peroxisome proliferatoractivated receptor gamma (PPAR- $\gamma$ ) agonist with insulin-sensitizing effects has been shown to improve aminotransferases, steatosis, inflammation, and ballooning in patients with $\mathrm{NASH}$ and prediabetes or T2DM ${ }^{41}$ (https://clinicaltrials.gov/ct2/show/ NCT00227110). In another clinical trial ${ }^{42}$ (PIVENS, Clinical trial NCT00063622, https:/clinicaltrials.gov/ct2/show/ NCT00063622) pioglitazone failed to show benefit over placebo for the histological features of NASH thought it improved some secondary outcomes (liver enzymes). Due to significant side effects of pioglitazone (weight gain ${ }^{43}$ and bone fractures in women ${ }^{44}$ ) both National Institute for Health and Care Excellence (NICE) and American Association for the Study of Liver Diseases (AASLD) guidelines recommend careful evaluation of risk and benefit and specific administration of pioglitazone to patients with established $\mathrm{NASH}^{40}$

\section{Glucagon-like peptide-1 (GLP-1) analogues}

In a published randomized, placebo-controlled trial consisting of 52 patients with biopsy-proven NASH, treatment with liraglutide administered subcutaneously oncedaily for 48 weeks was related to improved NASH and less progression of fibrosis ${ }^{45}$ (LEAN, Clinical trial NCT01237119, https://clinicaltrials.gov/ct2/show/NCT01237119). Similarly, in another clinical trial (LIRA-NAFLD study, Clinical 
TABLE 1. Current NAFLD pharmacotherapy and the clinical trials that demonstrated benefit

\begin{tabular}{|c|c|c|}
\hline $\begin{array}{l}\text { Current } \\
\text { Pharmacopherapy }\end{array}$ & Type of Study & Main Conclusion \\
\hline Pioglitazone & $\begin{array}{l}\text { A placebo-controlled trial of pioglitazone } \\
\text { in subjects with NASH } \\
\text { ClinicalTrials.gov Identifier: NCT00227110 }\end{array}$ & Improved aminotransferases, steatosis, inflammation, and ballooning ${ }^{41}$ \\
\hline \multirow[t]{2}{*}{ Liraglutide } & $\begin{array}{l}\text { A multicentre, double-blind, randomised, } \\
\text { placebo-controlled phase } 2 \text { study } \\
\text { LEAN, Clinical trial NCT01237119 }\end{array}$ & Improved NASH and slow progression of fibrosis ${ }^{45}$ \\
\hline & $\begin{array}{l}\text { LIRA-NAFLD study, Clinical trial } \\
\text { NCT02721888 }\end{array}$ & $\begin{array}{l}\text { Reduced liver fat deposits in patients with inadequately controlled } \\
\text { type } 2 \text { diabetes }{ }^{46}\end{array}$ \\
\hline Atorvastatin & $\begin{array}{l}\text { Post-hoc analysis } \\
\text { GREek Atorvastatin and Coronary-heart- } \\
\text { disease Evaluation (GREACE) study }\end{array}$ & $\begin{array}{l}\text { Atorvastatin in coronary heart disease patient ameliorates NAFLD and } \\
\text { NASH and reduces cardiovascular disease events }{ }^{47,48}\end{array}$ \\
\hline Fenofibrate & $\begin{array}{l}\text { Placebo-controlled study in } 27 \text { patients } \\
\text { with NAFLD }\end{array}$ & Fenofibrate had no effect on hepatic triglyceride content ${ }^{51}$ \\
\hline $\begin{array}{l}\text { Fenofibrate with } \\
\text { Atorvastatin }\end{array}$ & $\begin{array}{l}\text { A randomised study in } 186 \text { patients with } \\
\text { metabolic syndrome and NAFLD }\end{array}$ & $\begin{array}{l}\text { The combination was not more effective than atorvastatin } \\
\text { monotherapy in reducing transaminase levels and liver echogenicity }{ }^{52}\end{array}$ \\
\hline Ezetimibe & Meta-analysis & $\begin{array}{l}\text { Ezetimibe attenuated serum liver enzymes, hepatic steatosis and } \\
\text { ballooning in six studies. Interestingly, hepatocyte ballooning was } \\
\text { reduced only in randomized-control trials }{ }^{57}\end{array}$ \\
\hline \multirow[t]{3}{*}{ Vitamin $\mathrm{E}$} & Meta-analysis & $\begin{array}{l}\text { Vitamin E supplementation had a significant and positive effect in } \\
\text { the improvement of steatosis, ballooning degeneration, lobular } \\
\text { inflammation and fibrosis in patients with } \mathrm{NASH}^{58}\end{array}$ \\
\hline & $\begin{array}{l}\text { Randomized placebo-controlled trial of } \\
\text { ursodeoxycholic acid with vitamin E in } \\
\text { NASH }\end{array}$ & $\begin{array}{l}\text { Two years of treatment with ursodeoxycholic acid in combination with } \\
\text { vitamin E improved laboratory values and hepatic steatosis of patients } \\
\text { with } \mathrm{NASH}^{59}\end{array}$ \\
\hline & $\begin{array}{l}\text { Randomized placebo-controlled trial of } \\
\text { pioglitazone and vitamin E } \\
\text { PIVENS, Clinical trial NCT00063622 }\end{array}$ & $\begin{array}{l}\text { Vitamin E therapy in patients with NASH and without diabetes was } \\
\text { associated with a significantly higher rate of improvement in NASH }{ }^{42}\end{array}$ \\
\hline
\end{tabular}

TABLE 2. Experimental drugs currently in clinical trials for NAFLD treatment

\begin{tabular}{|c|c|c|c|}
\hline $\begin{array}{l}\text { Future } \\
\text { Pharmacotherapy }\end{array}$ & $\begin{array}{l}\text { Pharmacological } \\
\text { target }\end{array}$ & Type of Study & Main conclusion \\
\hline \multirow[t]{2}{*}{ Obeticholic acid } & $\begin{array}{l}\text { Agonist of bile acid- } \\
\text { activated Farnesoid X } \\
\text { Receptor (FxR) }\end{array}$ & $\begin{array}{l}\text { A multicentre, randomized, placebo- } \\
\text { controlled trial } \\
\text { (FLINT, Clinical trial NCT01265498) }\end{array}$ & $\begin{array}{l}\text { The } 45 \% \text { of patients in the obeticholic acid } \\
\text { group for } 72 \text { weeks had improved liver } \\
\text { histology compared with } 21 \% \text { of patients } \\
\text { in the placebo group }\end{array}$ \\
\hline & & $\begin{array}{l}\text { A phase 3, double-blind, randomized, long- } \\
\text { term, placebo-controlled, multicenter study } \\
\text { (REGENERATE, Clinical trial NCT02548351) }\end{array}$ & $\begin{array}{l}\text { This study will evaluate the effect of } \\
\text { Obeticholic Acid treatment compared to } \\
\text { placebo on histological improvement and } \\
\text { liver-related clinical outcomes in patients } \\
\text { with non-cirrhotic NASH with liver fibrosis }\end{array}$ \\
\hline Elafibranor & $\begin{array}{l}\text { Agonist of peroxisome } \\
\text { proliferator activated } \\
\text { receptors } a, \gamma, \delta \\
(\text { PPARs } a, \gamma, \delta)\end{array}$ & $\begin{array}{l}\text { A post-hoc analysis of data from trial of } \\
\text { patients with NASH } \\
\text { NASH, Clinical trial NCT01694849 }\end{array}$ & $\begin{array}{l}\text { Elafibranor was shown to be effective in } \\
\text { resolving NASH without worsening fibrosis } \\
\text { in patients with moderate to severe } \\
\mathrm{NASH}^{68}\end{array}$ \\
\hline Cenicriviroc & $\begin{array}{l}\text { Antagonist of } \mathrm{C}-\mathrm{C} \text { motif } \\
\text { chemokine receptor } \\
\text { (CCR) types } 2 \text { and } 5\end{array}$ & $\begin{array}{l}\text { A randomized, placebo-controlled trial of } \\
\text { cenicriviroc for treatment of NASH with } \\
\text { fibrosis } \\
\text { CENTAUR, Clinical trial NCT02217475 }\end{array}$ & $\begin{array}{l}\text { Cenicriviroc resulted in a significant } \\
\text { improvement in fibrosis without } \\
\text { worsening NASH after one year of } \\
\text { treatment }^{70}\end{array}$ \\
\hline
\end{tabular}


TABLE 3. Non-pharmacological and lifestyle interventions for the treatment and reversal of the early stages of NAFLD

\begin{tabular}{|c|c|c|}
\hline Food & Type of Study & Main conclusion \\
\hline Weight loss & $\begin{array}{l}\text { Observational } \\
\text { studies }\end{array}$ & $\begin{array}{l}\text { Weight loss improves hepatic histology. }{ }^{71,72} \text { According to the EASL, } \\
\text { NICE (https://www.nice.org.uk/guidance/ng } 49 \text { ), and AASLD }{ }^{40} \text { guidelines, } \\
\text { a } 7 \%-10 \% \text { weight loss is the target of most lifestyle interventions. Very } \\
\text { low-calorie diets should be avoided as they are considered unsustainable } \\
\text { and may pose a challenge to the patient }{ }^{62}\end{array}$ \\
\hline Bariatric surgery & $\begin{array}{l}\text { A cohort study with 1-year } \\
\text { follow-up }\end{array}$ & $\begin{array}{l}\text { Bariatric surgery (with more than } 30 \% \text { weight lose) cleared NASH in } 85 \% \\
\text { of patients and improved fibrosis in 34\% }\end{array}$ \\
\hline Coffee & Meta-analysis & $\begin{array}{l}\text { Increased coffee consumption may substantially reduce the risk of } \\
\text { cirrhosis. Coffee is rich in cafestol, a natural ligand for } \mathrm{FxR}^{74}\end{array}$ \\
\hline \multirow{2}{*}{$\begin{array}{l}\text { Ethanolic extract } \\
\text { of Prunus mume } \\
\text { (Japanesse Apricot) }\end{array}$} & $\begin{array}{l}\text { Interventional trial in } 58 \text { patients with } \\
\text { liver disorders of different cause }\end{array}$ & $\begin{array}{l}\text { The Japanese apricot extract reduced the AST, ALT and gamma-glutamyl } \\
\text { transferase levels in } 12 \text { weeks after treatment initiation }\end{array}$ \\
\hline & $\begin{array}{l}\text { A randomized, double-blind, placebo- } \\
\text { controlled study }\end{array}$ & $\begin{array}{l}\text { Beneficial and statistically significant effects of the extract were reported } \\
\text { on liver function, with decreases in ALT, AST, } \gamma \text {-GT and glycemia. Increase } \\
\text { in } \mathrm{HDL} \text { cholesterol and a decrease in LDL/HDL ratio and triglycerides }{ }^{76}\end{array}$ \\
\hline
\end{tabular}

trial NCT02721888, https://clinicaltrials.gov/ct2/show/ NCT02721888), it was reported that six months of treatment with $1.2 \mathrm{mg}$ liraglutide per day significantly reduced liver fat deposits in patients with inadequately controlled type 2 diabetes though there were no data on fibrosis progression. ${ }^{46}$ Both the AASLD ${ }^{40}$ and NICE (https://www.nice.org.uk/ guidance/ng49) recommendations indicate that there is still little evidence to support the use of GLP-1 analogues in NAFLD treatment. All other guidelines agree on this point; however they also state that further evidence may prove the efficacy of these drugs. ${ }^{34}$

\section{Lipid lowering strategies}

In a post-hoc analysis of The GREek Atorvastatin and Coronary-heart-disease Evaluation (GREACE) study, it was found that use of atorvastatin in coronary heart disease patient (CHD) ameliorates NAFLD and NASH and reduces cardiovascular disease (CVD) events. ${ }^{47,48}$ Regarding the safety of statin use in the treatment of NAFLD, all guidelines agree that statins are safe, even in patients with compensated cirrhosis. However, routine prescription of a statin is not suggested in patients with decompensated cirrhosis and acute liver failure. ${ }^{49}$ It should be noted that overall, clinical trials for the use of statins in NASH are limited and somewhat inconsistent, with liver enzymes improving modestly or not at all and variable effects on histology. ${ }^{50}$ Regarding the effects of fibrates on NAFLD, in a placebocontrolled study in 27 patients with NAFLD, fenofibrate had no effect on hepatic triglyceride content ${ }^{51}$ while in a larger study in 186 patients with metabolic syndrome and NAFLD the combination of fenofibrate and atorvastatin was not more effective than atorvastatin monotherapy in reducing transaminase levels and liver echogenicity. ${ }^{52}$
Ezetimibe, another lipid-lowering medication showed promising effects in limited-scale clinical trials. ${ }^{53-56} \mathrm{~A}$ recent meta-analysis to evaluate the efficacy of ezetimibe in treating NAFLD and NASH suggested that ezetimibe attenuated serum liver enzymes, hepatic steatosis and ballooning in six studies. Interestingly, hepatocyte ballooning was reduced only in randomized-control trials. ${ }^{57}$ The study indicated that larger randomized placebo-controlled trials are necessary to determine the effects of ezetimibe on NAFLD and NASH. ${ }^{57}$

\section{Vitamin E}

The benefit of vitamin E in the treatment of NASH is attributed to its antioxidant activity. A systematic review and meta-analysis of clinical trials to examine the effects of vitamin E supplementation on liver histology in NASH concluded that vitamin E supplementation had a significant and positive effect in the improvement of steatosis, ballooning degeneration, lobular inflammation and fibrosis in patients with NASH..$^{58}$ Moreover, Dufour and colleagues showed that two years of treatment with ursodeoxycholic acid in combination with vitamin $\mathrm{E}$ improved laboratory values and hepatic steatosis of patients with NASH. ${ }^{59}$ Similarly, results from a randomized interventional placebocontrolled clinical trial indicated that vitamin $\mathrm{E}$ therapy in patients with NASH and without diabetes was associated with a significantly higher rate of improvement in nonalcoholic steatohepatitis ${ }^{42}$ (PIVENS, Clinical trial NCT00063622, https://clinicaltrials.gov/ct2/show/NCT00063622). It should be noted that there are concerns about the long-term effects of vitamin $E$ on prostate cancer in men over 50 years of age $^{60}$ and further studies for its overall long-term safety and efficacy are necessary. Vitamin E is recommended by 
both NICE and AASLD guidelines (limited to established $\mathrm{NASH}$ in the latter case $^{40}$ ). European Association for the Study of the Liver (EASL) and Italian Association for the Study of the Liver (AISF) guidelines call for more evidence before any recommendation can be made, ${ }^{39,61}$ while AsiaPacific guidelines advice against the use of vitamin E which is described as not beneficial by the current evidence. ${ }^{62}$

\section{DRUGS UNDER DEVELOPMENT}

Although current pharmacotherapy for NAFLD may seem limited and of doubtful efficacy, there is optimism that innovative safe and effective options for the management of the disease will be made available shortly. Indeed, specialized drugs are presently tested in clinical trials for the treatment of NAFLD, NASH and hepatic fibrosis. These drugs include obeticholic acid, elafibranor and cenicriviroc.

\section{Obeticholic acid}

Bile acid-activated Farnesoid $X$ Receptor ( $F x R)$ is a metabolically active nuclear receptor which regulates bile acid, lipid, and glucose metabolism, and contributes to inter-organ communication, in particular the enterohepatic signaling pathway, through bile acids and fibroblast growth factor-15/19 (FGF-15/19). ${ }^{63}$ Natural ligands for FxR include cafestol, a diterpenoid present in coffee beans, and chenodeoxycholic acid. FxR forms heterodimers with retinoid $X$ receptor $(R \times R)$, and upon activation by an appropriate ligand the complex translocates to the cell nucleus, where it binds to FxR response elements (FxREs) on DNA, acting as a transcription factor. The optimal DNA-binding sequence for the FxR/RxR heterodimer is an inverted repeat composed of two AGGTCA half-sites spaced by one nucleotide (IR-1). ${ }^{64}$ As a result, it increases insulin sensitivity, decreases hepatic gluconeogenesis, and protects against cholestasis-induced liver injury. ${ }^{65} \mathrm{~A}$ multicenter, double-blind, placebo-controlled, randomized phase $2 \mathrm{~b}$ trial of patients with NASH found that patients treated with obeticholic acid presented improved liver histology at 18 months of treatment compared to placebo (relative risk: 2.2; 95\% Cl: 1.4 to 3.3) ${ }^{65}$ (FLINT, Clinical trial NCT01265498, https://clinicaltrials.gov/ct2/show/NCT01265498). A serious side effect of the drug in the FLINT trial that may hinder its future development, was a significant deterioration of plasma lipid profile, specifically increased levels of total and LDL cholesterol (LDL-C) and decreased levels of HDL cholesterol (HDL-C), which were not corrected by concomitant use of statins. ${ }^{65}$ Whether these unfavorable lipid changes are associated with increased cardiovascular risk will be determined in a large phase 3 clinical trial that is currently in progress (REGENERATE, Clinical trial NCT02548351, https:// clinicaltrials.gov/ct2/show/NCT02548351).

\section{Elafibranor}

PPARs $(a, \gamma, \delta)$ are ligand-stimulated nuclear receptors that control gene expression by binding to their respective response elements (PPREs) within promoters in the DNA. PPARs form heterodimers with RxR and, upon binding of specific agonist, the complex translocates to the nucleus where it interact with the transcription machinery, affecting its rate and efficacy. ${ }^{66}$ PPARa is the pharmacological target of the hypolipidemic drug fenofibrate and PPARY is the pharmacological target for thiazolidinediones (ciglitazone, pioglitazone, rosiglitazone etc). PPAR $\delta$ is another member of the PPAR family that is known to shift body's energy preference from glucose to lipids, ${ }^{67}$ though no medicine targeting PPAR $\delta$ is currently approved. Elafibranor, a dual agonist for PPARa and $\delta$ which is currently in clinical trials has been shown to improve insulin sensitivity, glucose homeostasis, and lipid metabolism, and attenuates hepatic inflammation. In a multicenter, randomized, placebo-controlled phase $2 \mathrm{~b}$ trial, elafibranor was shown to be effective in resolving $\mathrm{NASH}$ without worsening fibrosis in patients with moderate to severe NASH ${ }^{68}$ (NASH, Clinical trial NCT01694849, https:// clinicaltrials.gov/ct2/show/NCT01694849). This experimental drug is presently in a phase 3 clinical trial in patients with NASH and fibrosis (REGENERATE, Clinical trial NCT02548351, https:/(clinicaltrials.gov/ct2/show/NCT02548351).

\section{Cenicriviroc}

Cenicriviroc is an antagonist of $\mathrm{C}-\mathrm{C}$ motif chemokine receptor (CCR) types 2 and 5, which promote anti-inflammatory and antifibrotic effects in the liver. ${ }^{69,70}$ The expected pharmacological effect of this medication is to reduce hepatic fibrosis. A randomized, double-blind, phase $2 \mathrm{~b}$ study found that cenicriviroc resulted in a significant improvement in fibrosis without worsening NASH after one year of treatment ${ }^{70}$ (CENTAUR, Clinical trial NCT02217475, https://clinicaltrials.gov/ct2/show/NCT02217475).

\section{THERAPEUTIC LIFESTYLE CHANGES}

Pharmacological management of NAFLD should be limited only to those patients with established NASH and fibrosis. For all other subjects with early manifestations of NAFLD the adoption of TLC, such as limited caloric intake, increased physical exercise, and weight-loss produce excellent results and is proposed by many guidelines as a first-line treatment. ${ }^{35,36}$

\section{Weight loss}

Indeed, weight loss has been reported as a key factor in improving hepatic histology. ${ }^{71,72}$ According to the EASL, ${ }^{39}$ NICE (https://www.nice.org.uk/guidance/ng49), and AASLD 40 guidelines, a 7\%-10\% weight loss is the target of most life- 
style interventions. Weight loss by a healthy diet such as the Mediterranean diet with a low calorie (1200-1600 kcal/d), low fat (less than $10 \%$ of saturated fatty acid) low carbohydrates ( $<50 \%$ of total $\mathrm{kcal})$, and rich in natural antioxidants is recommended. Very low-calorie diets should be avoided as they are considered unsustainable and may pose a challenge to the patient. ${ }^{62}$ Similarly, in morbidly obese individuals, bariatric surgery improves liver damage, including fibrosis, when significant weight loss is achieved (30\% or more). ${ }^{73}$

\section{Coffee}

Interestingly, natural foods and nutritional supplements have also shown significant benefit in the treatment and reversal of the first stages of NAFLD. Recently, it was reported that coffee consumption may reduce the risk of fibrosis progression and cirrhosis, as it was suggested by a metaanalysis of observational studies. ${ }^{74}$ Specifically, increasing coffee consumption by two cups per day was associated with a statistically significant reduction in the risk of cirrhosis. Coffee is rich in cafestol, a natural ligand for FxR.

\section{Prunus mume}

Similarly, a titrated ethanolic extract of Prunus mume (Japanesse Apricot) was shown to have favorable influence on hepatic enzymes both in animals and humans. ${ }^{75,76}$ The extract coded as MK615 is rich in polyphenols (chlorogenic acid) and triterpanes (oleanolic and ursolic acid) and showed a significant improvement of hepatic histology in tetrachloride-treated rats with concomitant reduction in aspartate aminotransferase (AST) and alanine aminotransferase (ALT) levels. ${ }^{75}$ When the same extract was used in patients with liver disorders, a significant reduction in AST, ALT and gamma-glutamyl transferase ( $\gamma$ GT) was noted 12 weeks after treatment initiation. ${ }^{75}$ In another, multicenter randomized, double-blind, parallel, placebo-controlled trial using healthy volunteers of both genders in hospitals from Italy, France and Switzerland, beneficial and statistically significant effects versus placebo were reported on liver function, with decreases in ALT (47\%), AST (7\%), Y-GT (15\%) and glycemia (11\%). In addition, MK615 also had a positive of plasma lipids with an increase in HDL cholesterol (13\%), and a decrease in LDL/HDL ratio (12\%) and triglycerides (8\%). As expected MK615 also exhibited antioxidant effects as shown by a decrease in oxidized glutathione, reduced/ oxidized cysteine-glycine, oxidized cysteine (intracellular pro-oxidant) and neopterin (inflammation biomarker). The no observed adverse effect level (NOAEL) for the ethanolic prunus mume extract was determined at $3.33 \mathrm{~g} / \mathrm{kg}$ of body weight in a subacute toxicity study. ${ }^{77}$

\section{CONCLUSIONS}

The treatment of NAFLD and most importantly its more severe and life-threatening manifestations of fibrosis and cirrhosis, face significant limitations and challenges. Today, no medicines have been approved to treat NAFLD, though experimental antiofibrotic drugs are in trials. Thus, at the pharmacological level, the disease is treated for its comorbidities with hypolipidemic (statins, ezetimibe) and antidiabetic medications (insulin sensitizers, incretin analogues) and possibly vitamin E. However, the degree of efficacy of each of these medications differs significantly in the different guidelines issued by international medical associations. TLC remains a leading strategy for NAFLD treatment and prevention especially in the early stages. In the context of therapeutic dietary interventions, low calorie diets (1200-1600 kcal/d) containing low fat (less than $10 \%$ of saturated fatty acid) low carbohydrates $(<50 \%$ of total kcal), and natural antioxidants (such as coffee and the MK615 Prunus mume extract) are increasingly recognized to improve liver enzymes (AST, ALT, YGT) and lipid markers (HDL, LDL, triglycerides) associated with early NAFLD development and progression. ${ }^{74-76}$

\section{Conflict of interest statement}

The authors have no conflict of interest to disclose.

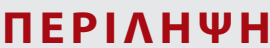

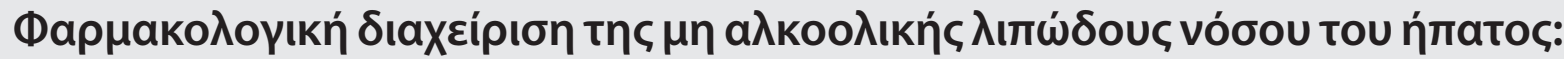

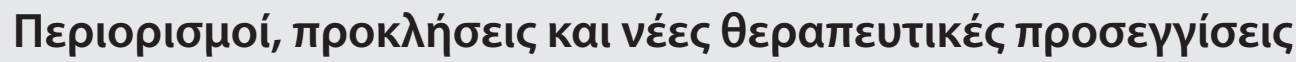

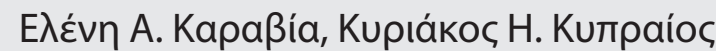

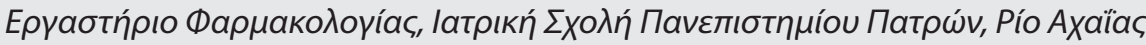

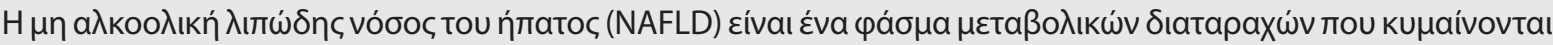

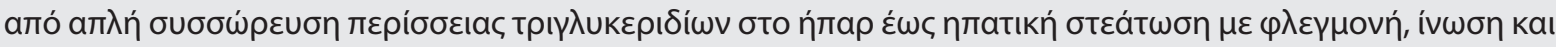

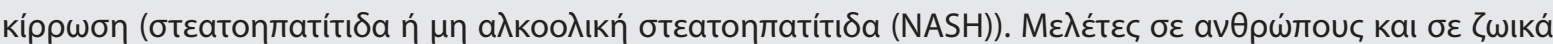




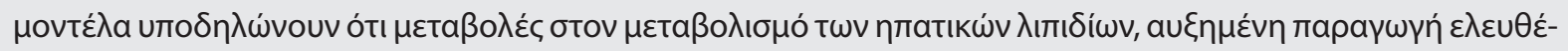

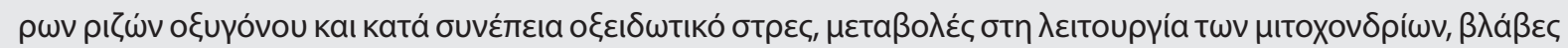

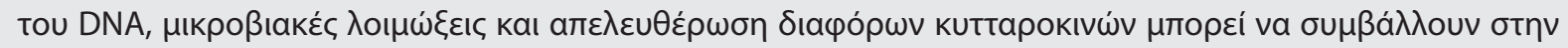

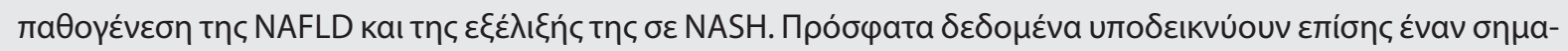

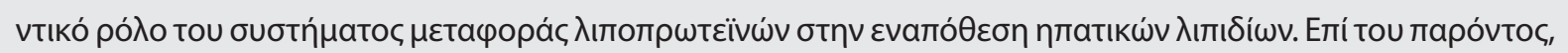

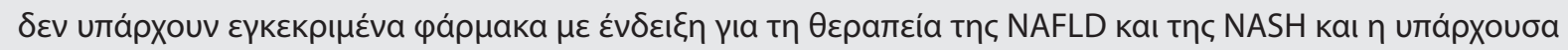

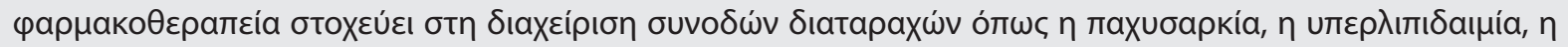

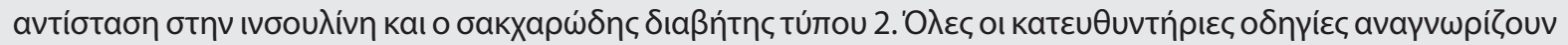

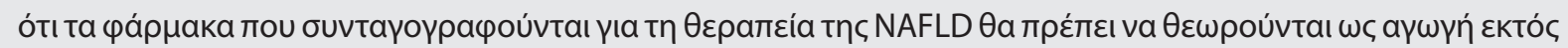

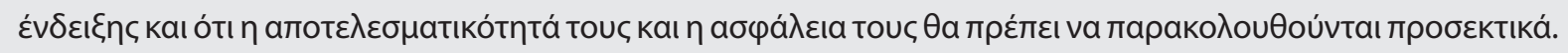

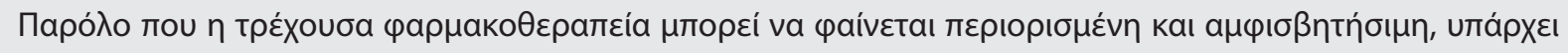

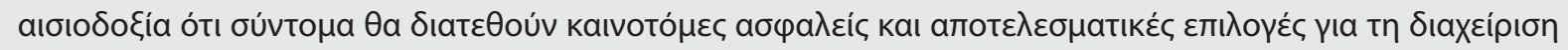

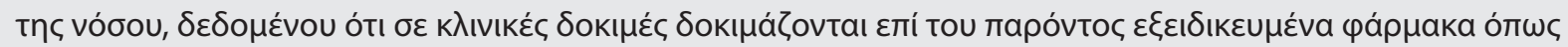

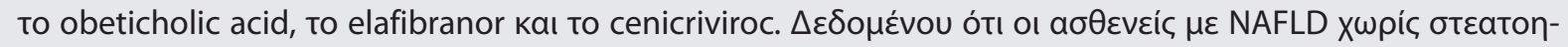

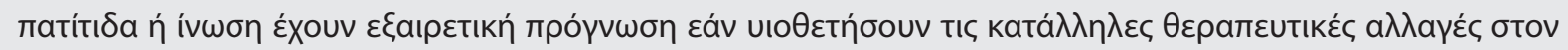

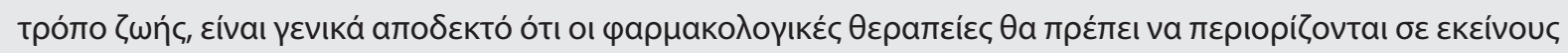

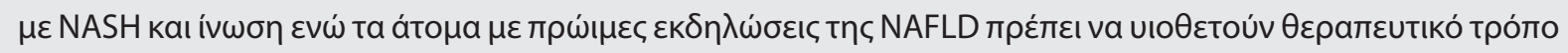
¿

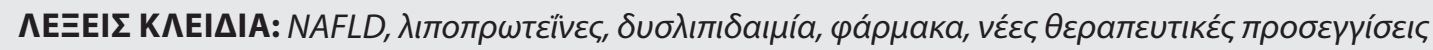

\section{REFERENCES}

1. Preiss D, Sattar N. Non-alcoholic fatty liver disease: an overview of prevalence, diagnosis, pathogenesis and treatment considerations. Clin Sci (Lond). 2008 Sep;115(5):141-50.

2. Angulo P. Nonalcoholic fatty liver disease. N Engl J Med. 2002 Apr;346(16):1221-31.

3. Hamaguchi M, Kojima T, Takeda N, Nakagawa T, Taniguchi $\mathrm{H}$, Fujii K, et al. The metabolic syndrome as a predictor of nonalcoholic fatty liver disease. Ann Intern Med. 2005 Nov;143(10):722-8.

4. Marchesini G, Brizi M, Bianchi G, Tomassetti S, Bugianes E, Lenzi $M$, et al. Nonalcoholic fatty liver disease: a feature of the metabolic syndrome. Diabetes. 2001 Aug;50(8):1844-50.

5. Wattacheril J, Sanyal AJ. Lean NAFLD: an underrecognized outlier. Curr Hepatol Rep. 2016 Jun;15(2):134-9.

6. Baran B, Akyüz F. Non-alcoholic fatty liver disease: what has changed in the treatment since the beginning? World J Gastroenterol. 2014 Oct; 20(39): 14219-29.

7. Vernon G, Baranova A, Younossi ZM. Systematic review: the epidemiology and natural history of non-alcoholic fatty liver disease and non-alcoholic steatohepatitis in adults. Aliment Pharmacol Ther. 2011 Aug;34(3):274-85.

8. Imprialos K, Stavropoulos K, Doumas M, Sfikas G, Koumaras C, Katsiki N, et al. Is non-alcoholic steatohepatitis in lean people a risk factor for liver or cardiovascular disease? Hell J Atheroscler 2017 Oct-Dec;(8):110-20.

9. Chitturi S, Farrell GC. Etiopathogenesis of nonalcoholic steatohepatitis. Semin Liver Dis. 2001;21(1):27-41.

10. Browning JD, Horton JD. Molecular mediators of hepatic steatosis and liver injury. J Clin Invest. 2004 Jul;1 14(2):147-52.

11. Byrne CD, Olufadi R, Bruce KD, Cagampang FR, Ahmed
$\mathrm{MH}$. Metabolic disturbances in non-alcoholic fatty liver disease. Clin Sci (Lond). 2009 Apr;116(7):539-64.

12. Cortes VA, Curtis DE, Sukumaran S, Shao X, Parameswara V, Rashid S, et al. Molecular mechanisms of hepatic steatosis and insulin resistance in the AGPAT2-deficient mouse model of congenital generalized lipodystrophy. Cell Metab. 2009 Feb;9(2):165-76.

13. Tirosh O, Artan A, Aharoni-Simon M, Ramadori G, Madar Z. Impaired liver glucose production in a murine model of steatosis and endotoxemia: protection by inducible nitric oxide synthase. Antioxid Redox Signal. 2010 Jul;13(1):13-26.

14. Zannis VI, Kypreos KE, Chroni A, Kardassis D, Zanni EE. Lipoproteins and atherogenesis. In: Loscalzo J, editor. Molecular Mechanisms of Atherosclerosis. 1st ed. Taylor \& Francis, New York, NY; c2004 p. 111-74.

15. Tsompanidi EM, Brinkmeier MS, Fotiadou EH, Giakoumi SM, Kypreos KE. HDL biogenesis and functions: Role of HDL quality and quantity in atherosclerosis. Atherosclerosis. 2010 Jan;208(1):3-9.

16. Soutar AK, Garner CW, Baker HN, Sparrow JT, Jackson RL, Gotto AM, et al. Effect of the human plasma apolipoproteins and phosphatidylcholine acyl donor on the activity of lecithin: cholesterol acyltransferase. Biochemistry. 1975 Jul; 14:3057-64.

17. Chroni A, Liu T, Gorshkova I, Kan HY, Uehara Y, von Eckardstein A, et al. The central helices of apoA-I can promote ATP-binding cassette transporter A1 (ABCA1)-mediated lipid efflux. Amino acid residues 220-231 of the wildtype apoA-I are required for lipid efflux in vitro and high density lipoprotein formation in vivo. J Biol Chem. 2003 Feb;278(9):6719-30.

18. Fitzgerald ML, Morris AL, Chroni A, Mendez AJ, Zannis VI, 
Freeman MW. ABCA1 and amphipathic apolipoproteins form high-affinity molecular complexes required for cholesterol efflux. J Lipid Res. 2004 Feb;45(2):287-94.

19. Van Eck M, Pennings M, Hoekstra M, Out R, van Berkel TJ. Scavenger receptor $\mathrm{BI}$ and ATP-binding cassette transporter A1 in reverse cholesterol transport and atherosclerosis. Curr Opin Lipidol. 2005 Jun;16(3):307-15.

20. Krieger M. Scavenger receptor class B type I is a multiligand HDL receptor that influences diverse physiologic systems. J Clin Invest. 2001 Sep; 108(6):793-7.

21. Liu T, Krieger M, Kan HY, Zannis VI. The effects of mutations in helices 4 and 6 of apoA-I on scavenger receptor class $B$ type I (SR-BI)-mediated cholesterol efflux suggest that formation of a productive complex between reconstituted high density lipoprotein and SR-BI is required for efficient lipid transport. J Biol Chem. 2002 Jun;277(24):21576-84.

22. Karavia EA, Papachristou DJ, Liopeta K, Triantaphyllidou IE, Dimitrakopoulos O, Kypreos KE. Apolipoprotein A-I modulates processes associated with diet-induced nonalcoholic fatty liver disease in mice. Mol Med. 2012 Sep;18:901-12.

23. Liu W, Qin L, Yu H, Lv F, Wang Y. Apolipoprotein A-I and adenosine triphosphate-binding cassette transporter $\mathrm{A} 1$ expression alleviates lipid accumulation in hepatocytes. J Gastroenterol Hepatol. 2014 Mar;29(3):614-22.

24. Wang W, Zhou W, Wang B, Zhu H, Ye L, Feng M. Antioxidant effect of apolipoprotein A-I on high-fat diet-induced non-alcoholic fatty liver disease in rabbits, Acta Biochim Biophys Sin (Shanghai). 2013 Feb;45(2):95-103.

25. Brewer HB Jr, Lux SE, Ronan R, John KM. Amino acid sequence of human apoLp-GIn-II (apoA-II), an apolipoprotein isolated from the high-density lipoprotein complex. Proc Natl Acad Sci U S A. 1972 May;69(5):1304-8.

26. Castellani LW, Goto AM, Lusis AJ. Studies with apolipoprotein A-II transgenic mice indicate a role for HDLs in adiposity and insulin resistance. Diabetes. 2001 Mar;50(3):643-51.

27. Zaki ME, Amr KS, Abdel-Hamid M. APOA2 Polymorphism in Relation to Obesity and Lipid Metabolism. Cholesterol. 2013. Available from: http://dx.doi. org/10.1155/2013/289481.

28. Lara-Castro C, Hunter GR, Lovejoy JC, Gower BA, Fernandez JR. Apolipoprotein A-Il polymorphism and visceral adiposity in African-American and white women. Obes Res. 2005 Mar;13(3):507-12.

29. Karavia EA, Papachristou DJ, Kotsikogianni I, Triantafyllidou IE, Kypreos KE. Lecithin/cholesterol acyltransferase modulates diet-induced hepatic deposition of triglycerides in mice. J Nutr Biochem. 2013 Mar;24(3):567-77.

30. Karavia EA, Papachristou NI, Sakellaropoulos GC, Xepapadaki E, Papamichail E, Petropoulou PI, et al. Scavenger Receptor Class B Type I Regulates Plasma Apolipoprotein E Levels and Dietary Lipid Deposition to the Liver. Biochemistry. 2015 Sep 15;54(36):5605-16.

31. Santos RD, Valenti L, Romeo S. Does nonalcoholic fatty liver disease cause cardiovascular disease? Current knowledge and gaps, Atherosclerosis. 2019 Mar;282:1 10-20.

32. Stahl EP, Dhindsa DS, Lee SK, Sandesara PB, Chalasani NP, Sperling LS. Nonalcoholic Fatty Liver Disease and the Heart: JACC State-of-the-Art Review. J Am Coll Cardiol. 2019 Mar;73(8):948-63.

33. Karavia EA, Papachristou DJ, Kotsikogianni I, Giopanou I, Kypreos KE. Deficiency in apolipoprotein E has a protective effect on diet-induced nonalcoholic fatty liver disease in mice. FEBS J. 2011 Sep;278(17):3119-29.

34. Leoni S, Tovoli F, Napoli L, Serio I, Ferri S, Bolondi L. Current guidelines for the management of non-alcoholic fatty liver disease: A systematic review with comparative analysis. World J Gastroenterol. 2018 Aug;24(30):3361-73.

35. Promrat $K$, Kleiner DE, Niemeier HM, Jackvony E, Kearns $\mathrm{M}$, Wands JR, et al. Randomized controlled trial testing the effects of weight loss on nonalcoholic steatohepatitis. Hepatology. 2010 Jan;51(1):121-9.

36. Vilar-Gomez E, Martinez-Perez Y, Calzadilla-Bertot L, TorresGonzalez A, Gra-Oramas B, Gonzalez-Fabian L, et al. Weight loss through lifestyle modification significantly reduces features of nonalcoholic steatohepatitis. Gastroenterology. 2015 Aug;149(2):367-78.

37. Bugianesi E, Gentilcore E, Manini R, Natale S, Vanni E, Villanova $\mathrm{N}$, et al. A randomized controlled trial of metformin versus vitamin $\mathrm{E}$ or prescriptive diet in nonalcoholic fatty liver disease. Am J Gastroenterol. 2005 May;100(5):1082-90.

38. Haukeland JW, Konopski Z, Eggesbo HB, von Volkmann HL, Raschpichler G, Bjoro K, et al. Metformin in patients with non-alcoholic fatty liver disease: a randomized, controlled trial. Scand J Gastroenterol. 2009;44(7):853-60.

39. EASL-EASD-EASO. Clinical Practice Guidelines for the management of non-alcoholic fatty liver disease. J Hepatol. 2016 Jun;64(6):1388-402.

40. Chalasani N, Younossi Z, Lavine JE, Charlton M, Cusi K, Rinella $M$, Harrison $S A$, et al. The diagnosis and management of nonalcoholic fatty liver disease: Practice guidance from the American Association for the Study of Liver Diseases. Hepatology. 2018 Jan;67(1):328-57.

41. Belfort R, Harrison SA, Brown K, Darland C, Finch J, Hardies $\mathrm{J}$, et al. A placebo-controlled trial of pioglitazone in subjects with nonalcoholic steatohepatitis. N Engl J Med. 2006 Nov;355(22):2297-307.

42. Sanyal AJ, Chalasani N, Kowdley KV, McCullough A, Diehl AM, Bass NM, et al. Pioglitazone, vitamin E, or placebo for nonalcoholic steatohepatitis. N Engl J Med. 2010 May;362(18):1675-85.

43. Cusi K, Orsak B, Bril F, Lomonaco R, Hecht J, Ortiz-Lopez C, et al. Long-Term Pioglitazone Treatment for Patients With Nonalcoholic Steatohepatitis and Prediabetes or Type 2 Diabetes Mellitus: A Randomized Trial. Ann Intern Med. 2016 Sep;165(5):305-15.

44. Viscoli $C M$, Inzucchi $S E$, Young LH, Insogna KL, Conwit $R$, Furie KL, et al. Pioglitazone and Risk for Bone Fracture: Safety Data From a Randomized Clinical Trial. J Clin Endocrinol Metab. 2017 Mar;102(3):914-22.

45. Armstrong MJ, Gaunt P, Aithal GP, Barton D, Hull D, Parker $R$, et al. Liraglutide safety and efficacy in patients with nonalcoholic steatohepatitis (LEAN): a multicentre, doubleblind, randomised, placebo-controlled phase 2 study, Lancet. 2016 Feb;387(10019):679-90.

46. Verges B, Duvillard L, Pais de Barros JP, Bouillet B, BaillotRudoni S, Rouland A, et al. Liraglutide Reduces Postprandial Hyperlipidemia by Increasing ApoB48 (Apolipoprotein B48) Catabolism and by Reducing ApoB48 Production in Patients With Type 2 Diabetes Mellitus. Arterioscler Thromb Vasc Biol. 2018 Sep;38(9):2198-2206.

47. Athyros VG, Papageorgiou AA, Mercouris BR, Athyrou VV, Symeonidis AN, Basayannis EO, et al. Treatment with 
atorvastatin to the National Cholesterol Educational Program goal versus 'usual' care in secondary coronary heart disease prevention. The GREek Atorvastatin and Coronary-heart-disease Evaluation (GREACE) study. Curr Med Res Opin. 2002;18(4):220-8.

48. Doumas M, Imprialos K, Dimakopoulou A, Stavropoulos $\mathrm{K}$, Binas A, Athyros VG. The Role of Statins in the Management of Nonalcoholic Fatty Liver Disease. Curr Pharm Des. 2018;24(38):4587-92.

49. Kumar S, Grace ND, Qamar AA. Statin use in patients with cirrhosis: a retrospective cohort study. Dig Dis Sci. 2014 Aug;59(8):1958-65.

50. Foster T, Budoff MJ, Saab S, Ahmadi N, Gordon C, Guerci $A D$. Atorvastatin and antioxidants for the treatment of nonalcoholic fatty liver disease: the St Francis Heart Study randomized clinical trial. Am J Gastroenterol. 2011 Jan;106(1):71-7.

51. Fabbrini E, Mohammed BS, Korenblat KM, Magkos F, McCrea J, Patterson BW, et al. Effect of fenofibrate and niacin on intrahepatic triglyceride content, very low-density lipoprotein kinetics, and insulin action in obese subjects with nonalcoholic fatty liver disease. J Clin Endocrinol Metab. 2010 Jun;95(6):2727-35.

52. Athyros VG, Mikhailidis DP, Didangelos TP, Giouleme OI, Liberopoulos EN, Karagiannis A, et al. Effect of multifactorial treatment on non-alcoholic fatty liver disease in metabolic syndrome: a randomised study. Curr Med Res Opin. 2006 May;22(5):873-83.

53. Takeshita Y, Takamura T, Honda M, Kita Y, Zen Y, Kato K, et al. The effects of ezetimibe on non-alcoholic fatty liver disease and glucose metabolism: a randomised controlled trial. Diabetologia. 2014 May;57(5):878-90.

54. Filippatos TD, Elisaf MS. Role of ezetimibe in non-alcoholic fatty liver disease. World J Hepatol. 2011 Oct;3(10):265-7.

55. Shiwa T, Kawanami Y, Yokoyama T, Moritani A, Hashimoto M, Gotoh T. The efficacy of ezetimibe on nonalcoholic fatty liver disease (NAFLD). Nihon Shokakibyo Gakkai Zasshi. 2011 Aug;108(8):1383-92.

56. Averna M. The effect of ezetimibe on NAFLD. Atheroscler Suppl. 2015 Feb;17:27-34.

57. Nakade $Y$, Murotani $K$, Inoue T, Kobayashi $Y$, Yamamoto T, Ishii N, et al. Ezetimibe for the treatment of non-alcoholic fatty liver disease: A meta-analysis. Hepatol Res. 2017 Dec;47(13):1417-28.

58. Xu R, Tao A, Zhang S, Deng Y, Chen G. Association between vitamin $E$ and non-alcoholic steatohepatitis: a metaanalysis. Int J Clin Exp Med. 2015 Mar;8(3):3924-34.

59. Dufour JF, Oneta CM, Gonvers JJ, Bihl F, Cerny A, Cereda JM, et al. Randomized placebo-controlled trial of ursodeoxycholic acid with vitamin e in nonalcoholic steatohepatitis. Clin Gastroenterol Hepatol. 2006 Dec;4(12):1537-43.

60. Abner EL, Schmitt FA, Mendiondo MS, Marcum JL, Kryscio RJ.Vitamin E and all-cause mortality: a meta-analysis. Curr Aging Sci. 2011 Jul;4(2):158-70.

61. AISF position paper on nonalcoholic fatty liver disease (NAFLD): Updates and future directions. Dig Liver Dis. 2017 May;49(5):471-83.

62. Chitturi S, Wong VW, Chan WK, Wong GL, Wong SK, Sollano $\mathrm{J}$, et al. The Asia-Pacific Working Party on Non-alcoholic Fatty Liver Disease guidelines 2017-Part 2: Management and special groups. J Gastroenterol Hepatol. 2018
Jan;33(1):86-98.

63. Han CY. Update on FXR Biology: Promising Therapeutic Target?, Int J Mol Sci [Internet]. 2018 Jul;19(7):2069. Available from: https://www.ncbi.nlm.nih.gov/pmc/articles/ PMC6073382/

64. Laffitte BA, Kast HR, Nguyen CM, Zavacki AM, Moore DD, Edwards PA. Identification of the DNA binding specificity and potential target genes for the farnesoid X-activated receptor. J Biol Chem. 2000 Apr;275:10638-47.

65. Neuschwander-Tetri BA, Loomba R, Sanyal AJ, Lavine JE, Van Natta ML, Abdelmalek MF, et al. Farnesoid X nuclear receptor ligand obeticholic acid for non-cirrhotic, non-alcoholic steatohepatitis (FLINT): a multicentre, randomised, placebocontrolled trial. Lancet. 2015 Mar;385(9972):956-65.

66. Berger J, Moller DE. The mechanisms of action of PPARs. Annu Rev Med. 2002;53:409-35

67. Brunmair B, Staniek K, Dorig J, Szocs Z, Stadlbauer K, Marian $V$, et al. Activation of PPAR-delta in isolated rat skeletal muscle switches fuel preference from glucose to fatty acids, Diabetologia. 2006 Nov;49(11):2713-22.

68. Ratziu V, Harrison SA, Francque S, Bedossa P, Lehert $P$, Serfaty $L$, et al. Elafibranor, an Agonist of the Peroxisome Proliferator-Activated Receptor-alpha and -delta, Induces Resolution of Nonalcoholic Steatohepatitis Without Fibrosis Worsening. Gastroenterology. 2016 May;150(5), 1147-59.

69. Sumida Y, Yoneda M. Current and future pharmacological therapies for NAFLD/NASH. J Gastroenterol. 2018 Mar;53(3):362-76.

70. Friedman SL, Ratziu V, Harrison SA, Abdelmalek MF, Aithal GP, Caballeria J, et al. A randomized, placebo-controlled trial of cenicriviroc for treatment of nonalcoholic steatohepatitis with fibrosis. Hepatology. 2018 May;67(5):1754-67.

71. Haufe S, Engeli S, Kast P, Bohnke J, Utz W, Haas V, Hermsdorf $M$, et al. Randomized comparison of reduced fat and reduced carbohydrate hypocaloric diets on intrahepatic fat in overweight and obese human subjects. Hepatology. 2011 May;53(5):1504-14.

72. Asrih M, Jornayvaz FR. Diets and nonalcoholic fatty liver disease: the good and the bad. Clin Nutr. 2014 Apr;33(2):18690.

73. Lassailly G, Caiazzo R, Buob D, Pigeyre M, Verkindt $H_{\text {, }}$ Labreuche J, et al. Bariatric Surgery Reduces Features of Nonalcoholic Steatohepatitis in Morbidly Obese Patients. Gastroenterology. 2015 Aug;149(2):379-88.

74. Kennedy OJ, Roderick P, Buchanan R, Fallowfield JA, Hayes PC, Parkes J. Systematic review with meta-analysis: coffee consumption and the risk of cirrhosis. Aliment Pharmacol Ther. 2016 Mar;43(5):562-74.

75. Hokari A, Ishikawa T, Tajiri H, Matsuda T, Ishii O, Matsumoto $\mathrm{N}$, et al. Efficacy of MK615 for the treatment of patients with liver disorders, World J. Gastroenterol. World J Gastroenterol. 2012 Aug;18(31):4118-26.

76. Beretta A, Accinni R, Dellanoce C, Tonini A, Cardot JM, Bussiere A. Efficacy of a Standardized Extract of Prunus mume in Liver Protection and Redox Homeostasis: A Randomized, Double-Blind, Placebo-Controlled Study. Phytother Res. 2016 Jun;30(6):949-55.

77. Lu B, Wu X, Dong Y, Gong J, Zhang Y. Mutagenicity and safety evaluation of ethanolic extract of Prunus mume. $J$ Food Sci. 2009 Nov-Dec;74(9):T82-8. 